Article

\title{
Impact of Missing Passive Microwave Sensors on Multi-Satellite Precipitation Retrieval Algorithm
}

\author{
Bin Yong ${ }^{1,2, *}$, Bo Chen ${ }^{1}$, Yang Hong ${ }^{3}$, Jonathan J. Gourley ${ }^{4}$ and Zhe Li $^{5}$
}

1 State Key Laboratory of Hydrology-Water Resources and Hydraulic Engineering, Hohai University, Nanjing 210098, China; E-Mail: chenbo_hhu@126.com

2 State Key Laboratory of Satellite Ocean Environment Dynamics, Second Institute of Oceanography, SOA, Hangzhou 310012, China

3 School of Civil Engineering and Environmental Sciences, University of Oklahoma, Norman, OK 73019, USA; E-Mail: yanghong@ou.edu

4 NOAA/National Severe Storms Laboratory, Norman, OK 73072, USA;

E-Mail: jj.gourley@noaa.gov

5 Department of Hydraulic Engineering, Tsinghua University, Beijing 100084, China; E-Mail: lizhe.tu@gmail.com

* Author to whom correspondence should be addressed; E-Mail: yongbin_hhu@126.com; Tel.: +86-25-8378-7485.

Academic Editors: Xin Li, Yuei-An Liou, Qinhuo Liu and Prasad S. Thenkabail

Received: 10 October 2014 / Accepted: 6 January 2015 / Published: 9 January 2015

\begin{abstract}
The impact of one or two missing passive microwave (PMW) input sensors on the end product of multi-satellite precipitation products is an interesting but obscure issue for both algorithm developers and data users. On 28 January 2013, the Version-7 TRMM Multi-satellite Precipitation Analysis (TMPA) products were reproduced and re-released by National Aeronautics and Space Administration (NASA) Goddard Space Flight Center because the Advanced Microwave Sounding Unit-B (AMSU-B) and the Special Sensor Microwave Imager-Sounder-F16 (SSMIS-F16) input data were unintentionally disregarded in the prior retrieval. Thus, this study investigates the sensitivity of TMPA algorithm results to missing PMW sensors by intercomparing the "early" and "late" Version-7 TMPA real-time (TMPA-RT) precipitation estimates (i.e., without and with AMSU-B, SSMIS-F16 sensors) with an independent high-density gauge network of 200 tipping-bucket rain gauges over the Chinese Jinghe river basin $\left(45,421 \mathrm{~km}^{2}\right)$. The retrieval counts and retrieval frequency of various PMW and Infrared (IR) sensors incorporated into the TMPA system were also
\end{abstract}


analyzed to identify and diagnose the impacts of sensor availability on the TMPA-RT retrieval accuracy. Results show that the incorporation of AMSU-B and SSMIS-F16 has substantially reduced systematic errors. The improvement exhibits rather strong seasonal and topographic dependencies. Our analyses suggest that one or two single PMW sensors might play a key role in affecting the end product of current combined microwave-infrared precipitation estimates. This finding supports algorithm developers' current endeavor in spatiotemporally incorporating as many PMW sensors as possible in the multi-satellite precipitation retrieval system called Integrated Multi-satellitE Retrievals for Global Precipitation Measurement mission (IMERG). This study also recommends users of satellite precipitation products to switch to the newest Version-7 TMPA datasets and the forthcoming IMERG products whenever they become available.

Keywords: satellite precipitation; TRMM; GPM; IMERG; TMPA; hydrological application

\section{Background}

On 22 May 2012, the NASA Goddard Earth Sciences Data and Information Services Center announced the release of the Version-7 Tropical Rainfall Measuring Mission (TRMM) Multi-satellite Precipitation Analysis (TMPA) products, which have been anticipated by the satellite QPE-hydrology community. Compared to the previous Version-6, the Version-7 TMPA system integrated some new, important data sources from passive microwave (PMW), mainly including the Special Sensor Microwave Imager-Sounder (SSMIS) F16-17 and Microwave Humidity Sounder (MHS) N18-19 and Meteorological Operational satellite programme (MetOp) [1]. As for infrared (IR) sensors, the $0.07^{\circ}$ GridSat-B1 IR brightness temperature dataset was used for the period before the start of the CPC 4-km Merged Global IR Dataset (i.e., January 1998-February 2000) in the Version-7, which has no impact on the most recent 14 years of TMPA estimation. Secondly, the significantly improved Global Precipitation Climatology Centre (GPCC V2.2) full analysis was employed as the gauge analysis for climatological calibration of the TMPA real-time (TMPA-RT) estimates and the month-to-month gauge adjustments in the TMPA post-real-time (TMPA-PR) research products [2]. In addition, a specific latitude-band calibration scheme was carried out for all satellites in the blending techniques to estimate the merged precipitation. Therefore, the Version-7 TMPA datasets are generally considered an improvement over Version-6, and it will supersede all previous versions [3].

In November 2012, however, it was discovered that the data sources retrieved from 3 Advanced Microwave Sounding Unit-B (AMSU-B) sensors onboard NOAA-series satellites were unintentionally omitted in the first retrospective processing (referred to as "early" Version-7 hereafter) of both the TMPA-RT data series (3B40/41/42RT) and the official TMPA-PR research products (3B42/43V7), which resulted in a serious shortcoming in the inventory of microwave precipitation estimates used during 2000-2010. In fact, the data inputs coming from the SSMIS sensor on Defense Meteorological Satellite Program (DMSP) F16 platform were also missed in the first Version-7 processing (Note that the SSMIS-F16 missing was not mentioned in the TMPA technical documentations but we confirmed 
this by personal communication with George Huffman). Afterward, the TMPA developers quickly corrected this issue and reproduced these products.

On 28 January 2013, the second set (referred to as "late" Version-7 hereafter) of TMPA-RT (2000-now) and TMPA-PR (2000-2010) products were formally released. Meanwhile, the latest TMPA system also added a multi-channel passive microwave radiometer SSMIS on Defense Meteorological Satellite Program (DMSP) F16 platform, which provides vertical and horizontal polarization values for the SSMI-like 19, 22, 37, and $91 \mathrm{GHz}$ frequencies with conical scanning. As a matter of fact, the "early" Version-7 TMPA system consequently lacks two types of PMW input data sources (i.e., AMSU-B and SSMIS-F16) relative to the "late" Version-7.

Despite missing the AMSU-B and SSMIS-F16 inputs, there are still quite a few precipitation-related PMW sensors incorporated in the "early" Version-7 TMPA processing, including the TRMM Microwave Imager (TMI), the Advanced Microwave Scanning Radiometer for the Earth Observing System (AMSR-E) on Aqua, the Microwave Humidity Sounders (MHS) on NOAA-18/19 and MetOp-A, the Special Sensor Microwave/Imager (SSM/I) on DMSP-F13/14/15, and the SSMIS on DMSP-F17. As noted in previous documentations [4,5], these PMW-based inputs indicate the ice quantities in the hydrometeor profiles above the ground surface, but each individual sensor only provides a very sparse sampling of the time-space occurrence of precipitation. Moreover, during the TMPA data flow, these PMW inputs are first inter-calibrated to TRMM's combined PR and TMI retrievals, and then the PMW-calibrated IR-based rainfall estimates were used to fill PMW coverage gaps. Hence, the TMPA producers have reason to believe that the current merging system could cope rather reasonably with missing single input data source, and the precipitation averages over relatively larger spatiotemporal scales should be progressively less affected [3]. In addition, Turk et al. [6] has studied the impact of adding or deleting certain input sensors on the end product of the Naval Research Laboratory blended precipitation system (NRL-Blend) over the central United States. They found the overall quality of NRL blended satellite high-resolution precipitation product is not particularly sensitive to single missing PMW sensors. Asserting these findings to other algorithms are likely to give the impression that missing one or two single PMW sensors would not greatly influence the data accuracy of current multi-sensor precipitation estimates, even at the regional or basin scale. Thus, in this study, efforts are focused on comparing and analyzing the difference between "early" and "late" Version-7 TMPA estimates by using high-density gauge observations so as to quantitatively identify the impact of missing AMSU-B and SSMIS-F16 sensors on precipitation retrieval accuracy, which is of great interest to the TMPA developers. In Section 2, we introduce the study region and describe the data sources employed in the study. Section 3 discusses the results while a summary of the findings and conclusions are provided in Section 4.

\section{Study Area and Data Sources}

The basin chosen for this study is the Jinghe river basin located at the junction of the Shanxi and Gansu provinces and Ningxia Autonomous Region in the geometric center of the Chinese mainland between $34^{\circ} 14^{\prime} \mathrm{N}$ and $37^{\circ} 19^{\prime} \mathrm{N}, 106^{\circ} 14^{\prime} \mathrm{E}$ and $108^{\circ} 58^{\prime} \mathrm{E}$ (Figure 1). As a major tributary of the Yellow river, the Jinghe river originates from the middle part of the Liupan Mountains and flows approximately $455 \mathrm{~km}$ eastward into the Weihe river. The Jinghe river basin has a drainage area of $45,421 \mathrm{~km}^{2}$. The basin elevation ranges from $2904 \mathrm{~m}$ in the upstream mountainous area to $398 \mathrm{~m}$ above sea level at the 
channel outlet of the Taoyuan hydrological station, with the topography sloping from northwest to southeast. The climate of this basin is that of a typical temperature continental monsoon region, with its average annual temperature, precipitation, and runoff being about $8{ }^{\circ} \mathrm{C}, 514.7 \mathrm{~mm}$, and $37.5 \mathrm{~mm}$, respectively. In terms of annual precipitation, there is a smooth gradient from the northern semi-arid region (250 mm/year) increasing to the southern semi-humid zone $(560 \mathrm{~mm} / \mathrm{yr})$. Correspondingly, the vegetation types also exhibit a spatial transition from natural forests and grassland in the south, to sparse grassland and shrubs in the north. Summer and fall are the main rainy seasons accounting for about $72 \%-86 \%$ of the annual precipitation. Due to the increasing areas of bare soil and the reduced woody cover during the half past century, the Jinghe River basin has been a region of concern for rainfall-triggered soil erosion over China. Particularly in the rainy summer months (June-August), storms with high-intensity and long-duration rainfall frequently result in severe landslides and debris flows. Compared to other basins in the northern part of China, this semi-arid basin has an extraordinarily dense observation network, which can provide reliable ground verification for the satellite-derived precipitation estimates.

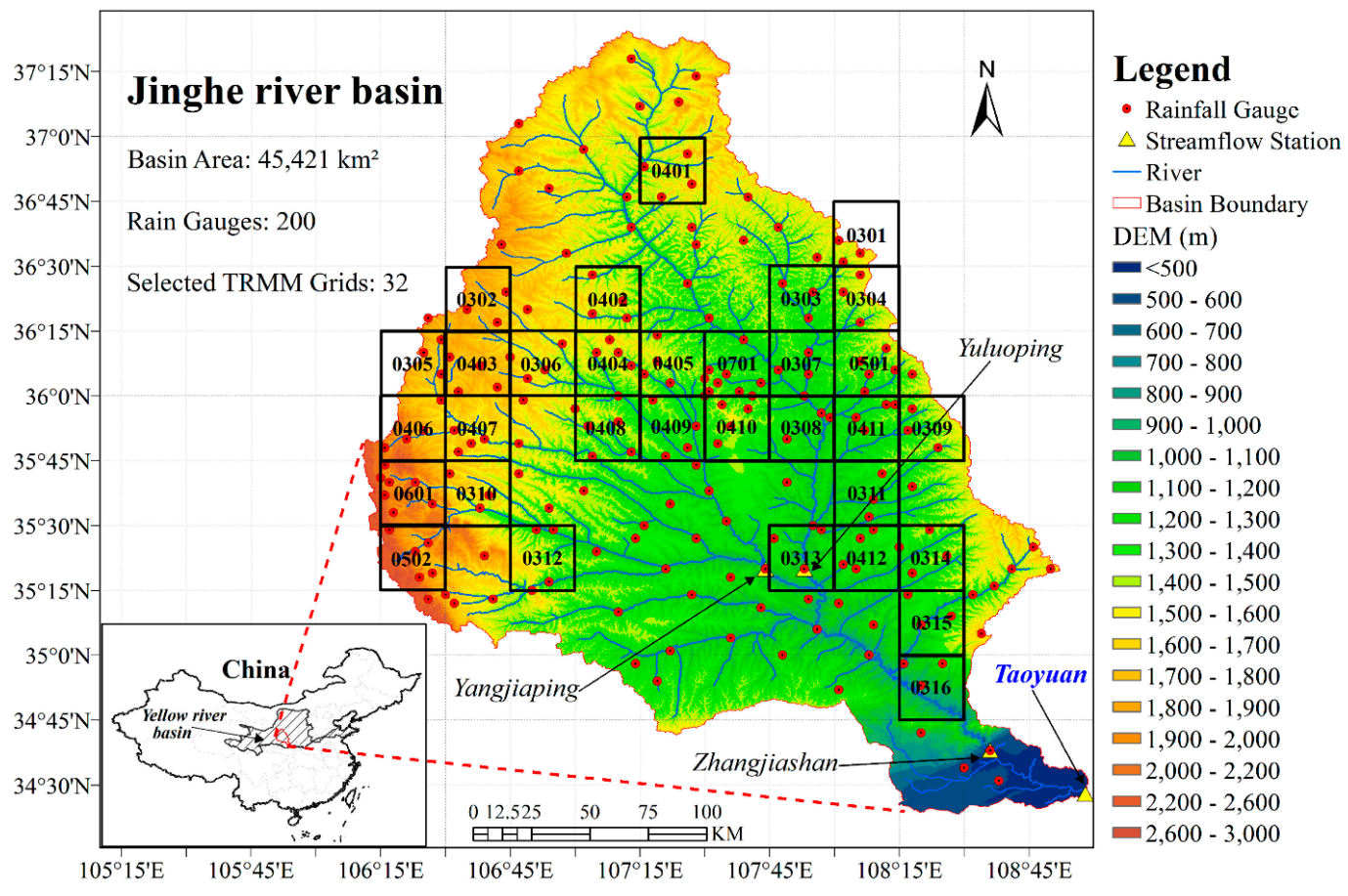

Figure 1. Map of the Jinghe river basin, rain gauges, streamflow stations, topography, and sampling strategies used in this study. Black squares represent the 32 selected $0.25^{\circ} \times 0.25^{\circ}$ grids for precipitation comparison. Numbers are grid IDs (e.g., 0301 indicates the first grid containing three gauges and 0302 represents the second grid containing three gauges and so on).

In this paper, the two high-resolution TMPA precipitation estimates we studied are the "early" and "late" Version-7 3B42RT products (for brevity, these will be referred to as the RTV7-R1 and RTV7-R2, respectively) at a fine scale of $3 \mathrm{hr}$ in time and $0.25^{\circ} \times 0.25^{\circ}$ in space. The RTV7-R1 and RTV7-R2 datasets were made available starting 1 March 2000 from [7]. These two TMPA-RT products will be compared at daily scale against a ground observation network, which is composed of 200 conventional 
tipping-bucket rain gauge sites spread evenly throughout the basin (see Figure 1). Considering the precisely temporal match from three hourly TMPA datasets to the daily estimates, the rainfall rates at 0000 and 2400 UTC were only accumulated for $1.5 \mathrm{~h}$ while rainfall rates at other times (i.e., 0300, 0600, 0900, 1200, 1500, 1800, and 2100 UTC) were accumulated for $3 \mathrm{~h}$. Based on the availability of the dense gauge observations within the Jinghe river basin, three years (January 2006-December 2008) were selected as the validation period. Additionally, it should be noted that this rain gauge network is maintained by the Chinese Ministry of Water Resources (CMWR). So, it is independent from the national standard stations operated by the China Meteorological Administration (CMA) whose data were employed for GPCC V2.2 full analysis in Version-7 TMPA system. To ensure high quality and continuity of observed rainfall data, a series of quality control and maintenance procedures were implemented, such as the preliminary visual inspection and a programming detection (see [8] for a detailed description). To further reduce the scale errors produced by direct comparison between the grid-scale satellite estimates and the point-scale gauge data, in this study we only selected gridboxes that contained at least three gauges and then used the mean value of all gauges inside each gridbox as the ground truth, as practiced by many previous studies [8-12]. Thus, thirty-two $0.25^{\circ} \times 0.25^{\circ}$ gridboxes corresponding to the TRMM combined product pixel resolution were selected over the entire basin (see Figure 1). Moreover, these representative gridboxes cover the diverse landscapes and terrain across the basin, including both the upstream mountainous area and the downstream flat lowland.

\section{Results and Discussions}

\subsection{Intercomparison of RTV7-R1 and RTV7-R2 against Gauge Observations}

The daily and monthly comparison of RTV7-R1 and RTV7-R2 versus gauge observations were first performed over thirty-two selected gridboxes and the whole basin average. Four representative statistical indices including Pearson linear correlation coefficient (CC), mean error (ME), root mean squared error (RMSE), relative bias (BIAS) are summarized in Table 1. As recommended by some previous studies [13-14], we adopted the common threshold of $1.0 \mathrm{~mm} /$ day to compute the daily contingency table statistics (i.e., probability of detection (POD), false alarm rate (FAR), and critical success index (CSI)). At daily time scale, both grid-based comparison and basin-averaged analysis indicate that RTV7-R2 had a better performance than RTV7-R1 with an apparently improved CC and reduced BIAS. Taking the gridded comparison for example, the CC value increases from 0.48 with RTV7-R1 to 0.57 with RTV7-R2 (increasing by approximately 19\%) and the BIAS drops from $41.59 \%$ to $20.37 \%$ (decreasing by about half). But, there is no evident difference between these two versions when examining the contingency table statistics. FAR of RTV7-R2 is only slightly lower than that of RTV7-R1 and they have the same POD values, which results in a little higher CSI with RTV7-R2 relative to RTV7-R1. This suggests that the incorporation of AMSU-B and SSMIS-F16 can effectively reduce the error and bias of TMPA-RT but failed to improve its skill in detecting rain events. Similarly, the monthly comparison shows that RTV7-R2 significantly outperformed RTV7-R1 with higher correlation and lower error and bias. 
Table 1. Statistical summary of two TMPA-RT precipitation estimates (RTV7-R1 and RTV7-R2) versus gauge observation at daily and monthly scales for grid-based and basin-averaged comparisons, respectively ${ }^{\mathrm{a}}$.

\begin{tabular}{cccccc}
\hline \multirow{2}{*}{ Time Scale } & \multirow{2}{*}{ Statistical Index } & \multicolumn{2}{c}{ Grid-Based Comparison } & \multicolumn{2}{c}{ Basin-Averaged Comparison } \\
\cline { 2 - 5 } & & RTV7-R1 & RTV7-R2 & RTV7-R1 & RTV7-R2 \\
\hline \multirow{5}{*}{ Daily } & CC & 0.48 & 0.57 & 0.66 & 0.74 \\
& RMSE (mm) & 5.00 & 4.11 & 2.92 & 2.30 \\
& ME (mm) & 0.53 & 0.26 & 0.55 & 0.28 \\
& BIAS (\%) & 41.59 & 20.37 & 43.99 & 21.99 \\
& POD & 0.65 & 0.65 & 0.83 & 0.83 \\
\hline \multirow{2}{*}{ Daily } & FAR & 0.50 & 0.45 & 0.46 & 0.40 \\
& CSI & 0.39 & 0.42 & 0.49 & 0.53 \\
\multirow{3}{*}{ Monthly } & CC & 0.69 & 0.77 & 0.82 & 0.88 \\
& RMSE (mm) & 37.79 & 29.20 & 27.99 & 19.91 \\
& ME (mm) & 16.00 & 7.83 & 16.65 & 8.39 \\
& BIAS (\%) & 41.59 & 20.37 & 43.99 & 21.99 \\
\hline
\end{tabular}

a Notation: A detailed description of all above statistical indices are provided in Table 1 of Yong et al. [8].

To investigate and intercompare the spatial error characteristics of the two versions, we employed two GIS interpolation techniques to generate continuous precipitation surfaces. First, the $0.25^{\circ} \times 0.25^{\circ}$ gridded satellite precipitation products ("early" RTV7-R1 and "late" RTV7-R2) were interpolated to $0.0625^{\circ} \times 0.0625^{\circ}$ datasets using a simple cropping approach (SCA, [15]). Then, the point-scale ground observations from 200 rain gauges distributed within the studied basin were interpolated onto the same grid using the Inverse Distance Weighting (IDW) method [16]. Although the simple SCA downscaling method might result in some local statistical errors, such relatively small, scale-induced differences do not make the comparison lose its statistical meaning or change the statistical tendency at spatial distribution. Importantly, this enabled us to compute gridded statistics based on the comparison of the two satellite versions to rain gauges at higher spatial resolution. Figure 2 exhibits the spatial distributions of three representative indices, CC, RMSE, and POD, which were computed from the SCA-interpolated daily precipitation datasets of two satellite products compared to IDW-interpolated ground observations on the same $0.0625^{\circ} \times 0.0625^{\circ}$-resolution grid over the entire basin. Generally speaking, better CC and lower RMSE values were found for RTV7-R2 than with RTV7-R1 (Figure 2a-d), while their POD distributions are quite similar (Figure 2e,f). This result closely corresponds to the statistical results in Table 1. Additionally, Figure $2 \mathrm{a}-\mathrm{d}$ reveals an interesting spatial error feature in that by using AMSU-B and SSMIS-F16 data, substantial improvements for RTV7-R2 mainly occurred in the southeast (low elevations), while there are not significant improvements in the northwest mountainous areas (high elevations). This is likely due to the large uncertainties of AMSU-B and SSMIS-F16 precipitation estimates over complex terrain. This finding agrees with the limitations of current PMW-based retrieval algorithms in mountainous, high-elevation regions as discussed in global scale evaluations [17-20]. 
Jinghe river basin

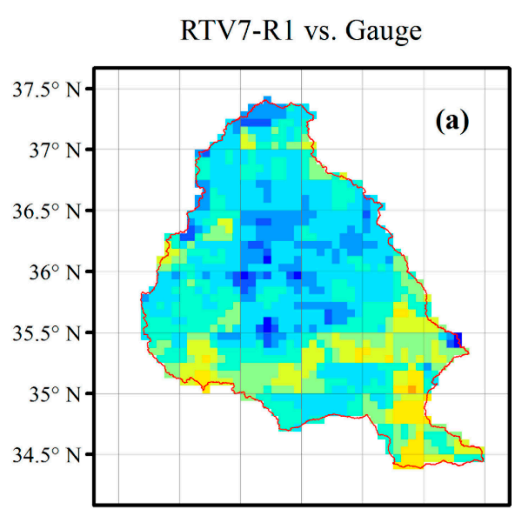

RTV7-R2 vs. Gauge
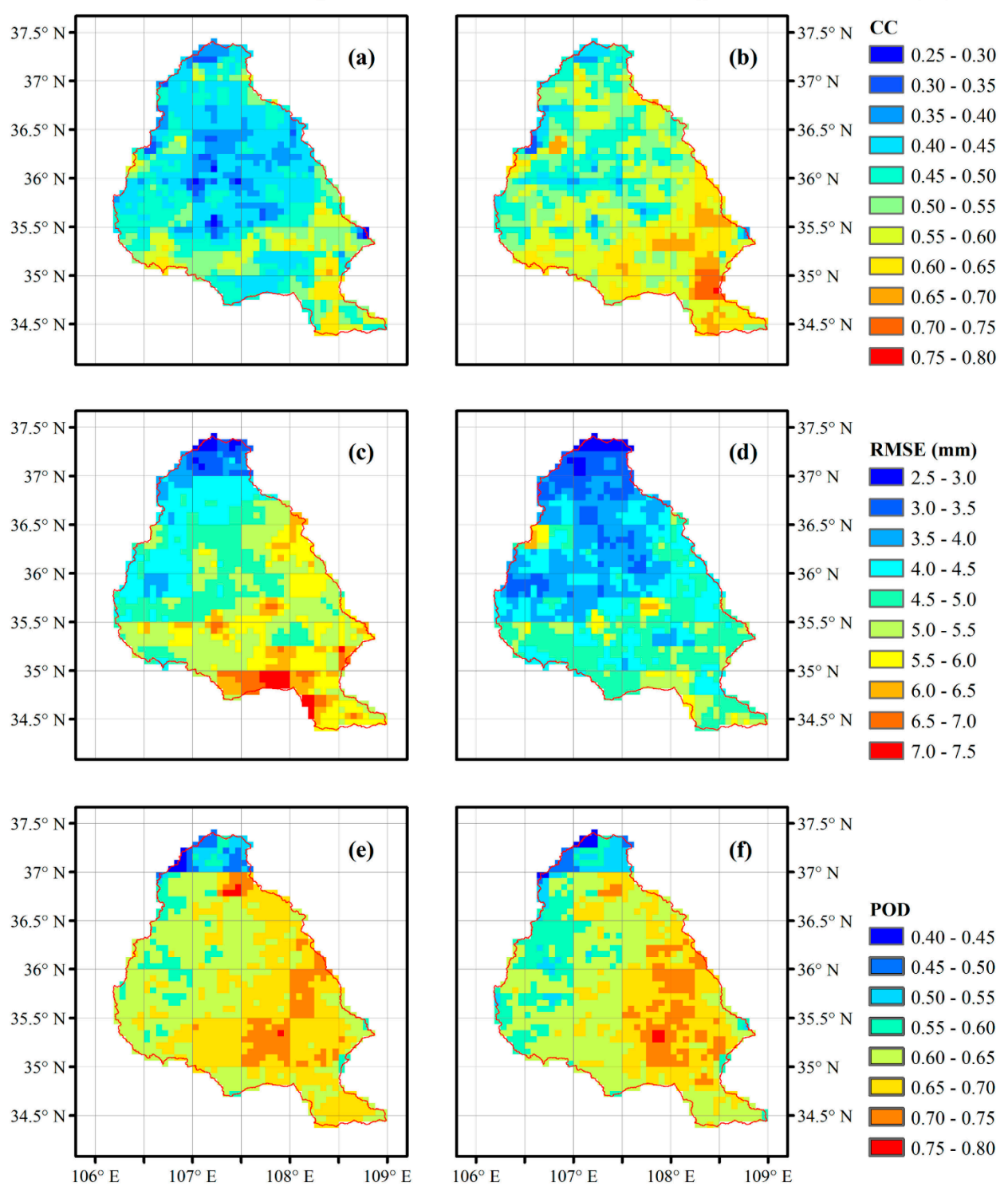

Figure 2. Spatial distributions of statistical indices computed from the (left) "early" RTV7-R1 and (right) "late" RTV7-R2 daily precipitation at $0.0625^{\circ} \times 0.0625^{\circ}$ resolution over the Jinghe river basin: $(\mathbf{a}, \mathbf{b})$ correlation coefficient $(\mathrm{CC}),(\mathbf{c}, \mathbf{d})$ root-mean-square error (RMSE), and (e,f) probability of detection (POD).

To further examine the temporal error features, we compared the monthly mean precipitation and the monthly variations of statistical indices of daily RTV7-R1 and RTV7-R2 against gauged observations for the 32 selected grid boxes in the Jinghe river basin (Figure 3). First, Figure 3a clearly shows that the monthly RTV7-R2 estimates have better agreement with gauge observations than RTV7-R1 throughout the validation period. Similar to the prior analyses, RTV7-R2 generally outperformed RTV7-R1 with higher correlation and lower error (Figure 3b-e). But the contingency table statistics (POD, FAR, and CSI) showed no clear differences between these two TMPA estimates (Figure $3 \mathrm{f}-\mathrm{h}$ ). This is consistent with our aforementioned statistical results. We also note that the improvement in error and bias of RTV7-R2 (relative to RTV7-R1) primarily occurred in winter (Figure 3c-e), while the increase of CC values 
mostly appeared in the summer months (Figure 3b). The differences between RTV7-R1 and RTV7-R2 exhibit rather strong seasonal dependencies. This finding was further confirmed by the statistical summary of the warm-cold season comparison in Table 2. For example, the BIAS decreased from $19.36 \%$ with RTV7-R1 to $11.60 \%$ with RTV7-R2 in summer, while the proportion dropped from $155.55 \%$ to only $8.15 \%$ in winter. The introduced AMSU-B and SSMIS-F16 data seem to yield the most effective improvements to TMPA's systematic bias in winter than in the other three seasons, at least in this mid-latitude study basin. This is consistent with Behrangi et al. [20] in which they discuss the value of AMSU precipitation over cold mountainous basins. Furthermore, they found that the IR techniques may provide higher detection skill over cold mountainous regions at the expense of higher false alarms.

To further examine the temporal error features, we compared the monthly mean precipitation and the monthly variations of statistical indices of daily RTV7-R1 and RTV7-R2 against gauged observations for the 32 selected grid boxes in the Jinghe river basin (Figure 3). First, Figure 3a clearly shows that the monthly RTV7-R2 estimates have better agreement with gauge observations than RTV7-R1 throughout the validation period. Similar to the prior analyses, RTV7-R2 generally outperformed RTV7-R1 with higher correlation and lower error (Figure 3b-e). But the contingency table statistics (POD, FAR, and CSI) showed no clear differences between these two TMPA estimates (Figure $3 f-h$ ). This is consistent with our aforementioned statistical results. We also note that the improvement in error and bias of RTV7-R2 (relative to RTV7-R1) primarily occurred in winter (Figure 3c-e), while the increase of CC values mostly appeared in the summer months (Figure 3b). The differences between RTV7-R1 and RTV7-R2 exhibit rather strong seasonal dependencies. This finding was further confirmed by the statistical summary of the warm-cold season comparison in Table 2. For example, the BIAS decreased from $19.36 \%$ with RTV7-R1 to $11.60 \%$ with RTV7-R2 in summer, while the proportion dropped from $155.55 \%$ to only $8.15 \%$ in winter. The introduced AMSU-B and SSMIS-F16 data seem to yield the most effective improvements to TMPA's systematic bias in winter than in the other three seasons, at least in this mid-latitude study basin. This is consistent with Behrangi et al. [20] in which they discuss the value of AMSU precipitation over cold mountainous basins. Furthermore, they found that the IR techniques may provide higher detection skill over cold mountainous regions at the expense of higher false alarms.

Table 2. Statistical indices (CC, RMSE, ME, BIAS, POD, FAR, and CSI) of daily RTV7-R1 and RTV7-R2 versus gauge for 32 selected gridboxes over the Jinghe river basin in summer (June-August (JJA)) and winter (December-February (DJF)), respectively.

\begin{tabular}{ccccc}
\hline \multirow{2}{*}{ Item } & \multicolumn{2}{c}{ Summer } & \multicolumn{2}{c}{ Winter } \\
\cline { 2 - 5 } & RTV7-R1 & RTV7-R2 & RTV7-R1 & RTV7-R2 \\
\hline CC & 0.56 & 0.61 & 0.27 & 0.17 \\
RMSE (mm) & 6.35 & 5.75 & 4.41 & 1.64 \\
ME (mm) & 0.49 & 0.30 & 0.39 & 0.02 \\
BIAS (\%) & 19.36 & 11.60 & 155.55 & 8.15 \\
POD & 0.77 & 0.77 & 0.22 & 0.16 \\
FAR & 0.37 & 0.34 & 0.72 & 0.73 \\
CSI & 0.53 & 0.55 & 0.14 & 0.11 \\
\hline
\end{tabular}




\section{Jinghe river basin}

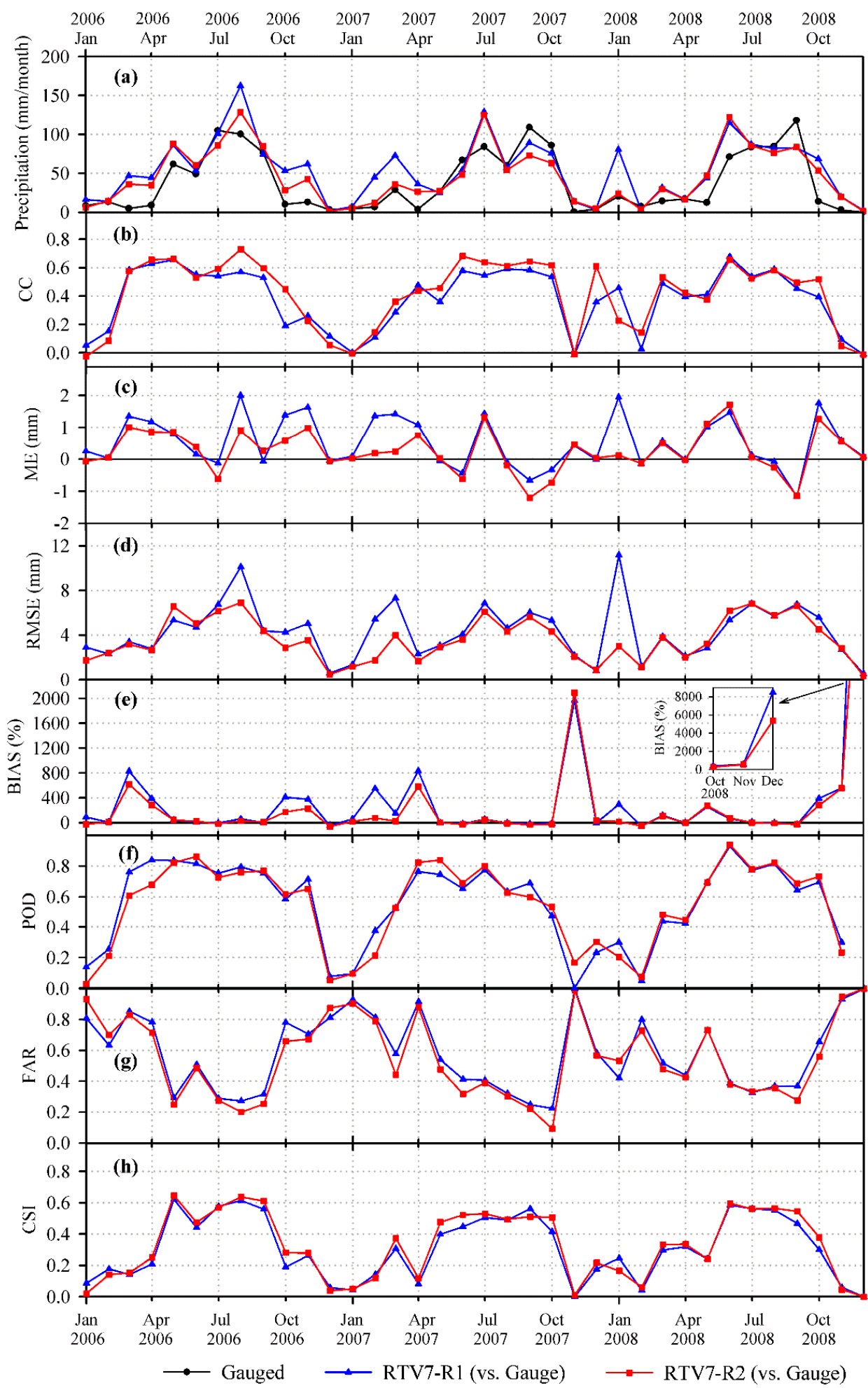

Figure 3. (a) Average monthly precipitation time series and (b-h) monthly variations of statistical indices of daily original and reprocessed 3B42RTV7 versus gauge observation for the 32 selected grid boxes: (b) correlation coefficient; (c) mean error; (d) root-mean-square error; (e) relative bias; (f) probability of detection; (g) false alarm ratio; and (h) critical success index. 


\subsection{Analysis of Sensor Retrieval Frequency for RTV7-R1 and RTV7-R2}

Up to this point, we have directly assessed and compared the two versions of TMPA-RT precipitation estimates against gauge observations. From all above statistical results, we can conclude that the "late" RTV7-R2 generally outperformed "early" RTV7-R1 during the three-year validation period, only except for relatively lower CC, POD, and CSI values with RTV7-R2 in winter (see Table 2). To help developers and users diagnose the impact of missing two important PMW sensors on TMPA-RT estimates, next we computed the retrieval counts and retrieval frequency of all satellite sensors that were incorporated into the TMPA processing over the Jinghe river basin (Table 3 ).

Table 3. Retrieval counts and retrieval frequency of all passive microwave and infrared sensors introduced into the TMPA Processing for all grids over the Jinghe river basin ${ }^{\text {a }}$.

\begin{tabular}{|c|c|c|c|c|c|c|c|}
\hline \multirow{2}{*}{$\begin{array}{l}\text { Source } \\
\text { Number } \\
\end{array}$} & \multirow{2}{*}{ Sensor } & \multirow{2}{*}{ Platform } & \multicolumn{2}{|c|}{ Retrieval Counts } & \multicolumn{2}{|c|}{ Retrieval Frequency } & \multirow{2}{*}{$\begin{array}{r}\text { Retrieval } \\
\text { Change }\end{array}$} \\
\hline & & & RTV7-R1 & RTV7-R2 & RTV7-R1 & RTV7-R2 & \\
\hline 0 & no observation & - & 2139 & 700 & $0.35 \%$ & $0.11 \%$ & $0.24 \%$ \\
\hline 1 & AMSU-B & NOAA-15/16/17 & 0 & 62,648 & 0 & $10.21 \%$ & $10.21 \%(\uparrow)$ \\
\hline 2 & TMI & TRMM & 61,946 & 52,107 & $10.09 \%$ & $8.49 \%$ & $1.60 \%(\uparrow)$ \\
\hline 3 & AMSR & Aqua & 73,899 & 73,899 & $12.04 \%$ & $12.04 \%$ & $0 \%$ \\
\hline 4 & SSMI & DMSP-F13/F14/F15 & 92,098 & 52,561 & $15.00 \%$ & $8.56 \%$ & $6.44 \%(\downarrow)$ \\
\hline 5 & F17 SSMIS & DMSP-F17 & 12,206 & 10,652 & $1.99 \%$ & $1.74 \%$ & $0.25 \%$ \\
\hline 6 & MHS & NOAA-18/19 MetOp-A & 110,280 & 34,348 & $17.97 \%$ & $5.60 \%$ & $12.37 \%(\downarrow)$ \\
\hline 7 & spare sounder 1 & - & 0 & 0 & 0 & 0 & $0 \%$ \\
\hline 8 & spare sounder 2 & - & 0 & 0 & 0 & 0 & $0 \%$ \\
\hline 9 & spare sounder 3 & - & 0 & 0 & 0 & 0 & $0 \%$ \\
\hline 10 & F16 SSMIS & DMSP-F16 & 0 & 33153 & 0 & $5.40 \%$ & $5.40 \%(\uparrow)$ \\
\hline 11 & F18 SSMIS & DMSP-F18 & 0 & 0 & 0 & 0 & $0 \%$ \\
\hline 12 & spare scanner 6 & - & 0 & 0 & 0 & 0 & $0 \%$ \\
\hline 30 & AMSU-B \& MHS avg. & - & 1154 & 83,582 & $0.19 \%$ & $13.62 \%$ & $13.43 \%(\uparrow)$ \\
\hline 31 & conical avg. & - & 62,093 & 113,941 & $10.12 \%$ & $18.56 \%$ & $8.44 \%(\uparrow)$ \\
\hline 50 & IR & $\begin{array}{c}\text { GOES/GMS/ } \\
\text { MTSat/Meteosat }\end{array}$ & 197,939 & 96,169 & $32.25 \%$ & $15.67 \%$ & $16.58 \%(\downarrow)$ \\
\hline $1,2, \ldots, 12+100$ & sparse-sample HQ & - & 6 & 0 & $0.001 \%$ & 0 & $0 \%$ \\
\hline \multicolumn{3}{|c|}{ Total retrieval for all sensors } & 613,760 & 613,760 & $100 \%$ & \multicolumn{2}{|r|}{$100 \%$} \\
\hline
\end{tabular}

a Notation: Two types of PMW sensors are currently available for TMPA, namely, cross-track scanning sounders (hereafter "sounder") including AMSU-B and HMS and conical scanning imagers (hereafter "imager") including TMI, AMSR, SSMI, and SSMIS. In the TMPA-RT file, the spare sounder 1, 2, and 3 denote three spare fields for the possibly introduced sounders in the future updates, while spare scanner 6 denote the spare field for scanner. Except for these microwave sensors/platforms, the international constellation of geosynchronous-orbit meteorological satellites including the Geosynchronous Operational Environmental Satellites (GOES, United States), the Geosynchronous Meteorological Satellite (GMS, Japan), subsequently Multi-functional Transport Satellite (MTSat, Japan), and the Meteorological Satellite (Meteosat, European Community) provide the infrared (IR) data on a 4 km-equivalent grid over the latitude band $60^{\circ} \mathrm{N}-\mathrm{S}$ for TMPA-RT.

In this study, 8768 data files of 3B42RT were used during the period of January 2006-December 2008. The calculating method of retrieval counts can be expressed as follows: There are 70 TMPA grid 
boxes $\left(0.25^{\circ} \times 0.25^{\circ}\right)$ covering the Jinghe river basin, so its corresponding total retrieval counts are: 70 Grids $\times 8768$ files $=613760$ counts. The Retrieval Frequency of a certain sensor source $(\mathrm{SFi})$ can be calculated as

$$
S F i=S C i / S C_{t o t a l} \times 100 \%
$$

where $S C_{i}$ is the retrieval counts of one sensor, $S C_{\text {total }}$ is the total retrieval counts for all sensors.

As documented in Appendix A of [2], the PMW sensor sources of TMPA can be separated into two types, namely, conical scanning imagers including TMI, AMSR, SSMI, and SSMIS, and cross-track scanning sounders including AMSU-B and HMS. From Table 3, one can see that there is little retrieval change from RTV7-R1 to RTV7-R2 for TMI, AMSR, F17 SSMIS, no observation, and sparse-sample HQ (all of their changes in retrieval frequency accounting for less than $2 \%$ of total retrievals). For simplicity, these source items could be omitted in the following sensor retrieval analysis.

In the TMPA system, each $0.25^{\circ} \times 0.25^{\circ}$ grid box will be filled with the "best" available data to produce the merged microwave and IR estimates. There is a priority order: (1) if any imagers viewed at a given grid box, they are used; (2) Else if any sounders viewed in the grid box, they are used; (3) Else if there are no any imager and sounder covering this grid box, the microwave-calibrated IR estimate is used. Moreover, if there is more than one overpass of the same microwave data type, all imagers (or all sounders) are lumped together and averaged for filling the grid box (corresponding to "conical average" and "AMSU-B\&MHS", respectively).

In practice, the main role of the newly added AMSU-B and SSMIS-F16 in the RTV7-R2 is to fill the partial areas previously covered by IR in the RTV7-R1. On the other hand, introducing AMSU-B data substantially boosts the content of sounder data. Due to the overlap of orbits in the 3-hourly windows that the TMPA system uses, the involvement of AMSU-B reduced the MHS-only cases, which mostly convert to AMSU-B\&MHS combinations. Similarly, adding SSMIS-F16 also boosts the content of imager data, but again due to overlap, the increase shows up in the imager average class (i.e., "conical avg.") and there is actually a decrease in the single-imager classes (e.g., TMI, SSMI, MHS, and SSMIS-F16). Note that AMSR is unchanged because it is isolated from other imagers in the TMPA algorithm. One can see that Table 3 just supports this conclusion. The sum of increased retrieval frequencies of AMSU-B (10.21\%) and SSMIS-F16 (5.40\%) with single overpass over the grids is approximately equivalent to that of decreased IR inputs (16.58\%). This suggests that during the evolution from RTV7-R1 to RTV7-R2, approximately two-thirds (62\%) of decreased retrievals for IR were replaced by AMSU-B, while the other reduction (33\%) could be attributed to the contribution of SSMIS-F16. On the other hand, the added AMSU-B data within the "averaged sounder" (i.e., "AMSU-B\&MHS") indirectly resulted in a decline of the retrieval frequency of the MHS sensor. The increased percentage of retrieval change of "AMSU-B\&MHS" (13.43\%) approximately equals the reduction with HMS (12.37\%). Similarly, the upward retrieval change of "conical average" (8.44\%) is almost same as those decreased values of SSMI (6.44\%) and TMI (1.60\%) together. The small residue of difference is likely resulted by the quality control action on SSMIS-F16 in the RTV7-R2 system.

Having seen that AMSU-B and SSMIS-F16 exhibit a better improvement for reducing the TMPA system bias in the winter compared to other seasons (refer to Figure 3 and Table 2), we consider that such a phenomenon might be closely related to the PMW retrievals for the winter snowfall. Hence, we further analyzed the observed snowy data in the cold season, and specifically investigated 
the snow-water equivalent (SWE) values in January 2008 since 10 snowing days occurred in this month (see Table 4).

Table 4. Cumulative snowmelt of gauge observation, RTV7-R1, and RTV7-R2 for two largest snowfall events (i.e., 11 January and 12 January) and the whole month in January 2008 at the 32 selected gridboxes and basin-average in Jinghe river basin, respectively ${ }^{\text {a }}$.

\begin{tabular}{ccccc}
\hline \multirow{2}{*}{ Item } & Evaluating Data & \multicolumn{3}{c}{ Cumulative Snowmelt (mm) } \\
\cline { 3 - 5 } & & Gauge & RTV7-R1 & RTV7-R2 \\
\hline \multirow{3}{*}{ Grid-Based } & 11 January & 5.36 & 9.63 & 2.19 \\
& 12 January & 4.55 & 43.30 & 4.28 \\
& Whole Month & 20.35 & 80.76 & 23.99 \\
\hline \multirow{3}{*}{ Basin-Average } & 11 January & 5.02 & 11.93 & 3.12 \\
& 12 January & 4.75 & 28.32 & 2.07 \\
& Whole Month & 20.79 & 65.38 & 22.67 \\
\hline \multicolumn{2}{c}{ Number of Snowing Days ${ }^{2}$} & 10 & 10 & 10 \\
\hline
\end{tabular}

a Notation: If the snowing observations of more than half rain gauge distributed within the whole basin exceed the threshold of $0.1 \mathrm{~mm}$, this day will be labeled as a "snowing day". With respect to snow observations, the local workers at the hydrological gauges introduced a known volume of warm water to thaw the snow in the standard vessel. So the liquid equivalency of the snow is computed as the total water volume minus the input warm water volume. The observers make a particular mark after the snow water equivalent digit in order to distinguish snow or rainfall as the precipitation type. Such manual but effective recording techniques can ensure the information of observed snow (or rain) and the data quality of SWE for our study.

Over the study basin, both grid-based and basin-averaged values for two largest snowy events in January 2008 and the whole month show that the SWEs from RTV7-R2 were much closer to gauge observations than that from RTV7-R1. For example, for the snowfall event that occurred on the 12 January 2008, RTV7-R1 dramatically overestimated gauge observations close to a factor of 10 over the 32 selected gridboxes (i.e., $43.30 \mathrm{~mm}$ for RTV7-R1 versus $4.55 \mathrm{~mm}$ for gauge). In contrast, the corresponding estimation of RTV7-R2 is $4.28 \mathrm{~mm}$, indicating underestimation of only about $6 \%$. Similarly, during the whole month, the RTV7-R1 estimation is three times larger than the observed SWE for the basin average, while RTV7-R2 has only a slight overestimation of $9 \%$.

Table 5 gives the detailed retrieval counts of various sensors for these two snowfall events and the whole month. Relative to the retrieval results in Table 3 for all seasons, the circumstance in winter looks more complicated. The most significant retrieval changes came from four types of sensors, i.e., SSMIS-F16, AMSU-B, MHS and IR. Taking the whole month as an example, the retrieval counts of SSMIS-F16 and AMSU-B increase from zero to 555 and 1547, respectively. Meanwhile, the IR has also increased 254 retrieval counts. While the retrieval counts of MHS decrease from 2934 of RTV7-R1 to 1990 (827 for pure MHS and 1163 for "AMSU-B\&MHS”) of RTV7-R2 (decreasing by 944 counts). In other words, the increase of SSMIS-F16, AMSU-B, and IR data used in RTV7-R2 jointly provides a $32 \%$ substitute for the missing MHS scans during the month of January 2008. Our experience is that AMSU-B and MHS are similar sensors and they might have identical performances, while the retrieval of IR generally do much worse than that of MHS. Therefore, we argue that the added imager SSMIS-F16, which were included into the PMW mosaics of RTV7-R2, replace partial MHS sounder 
overpasses and play a key role in improving the retrieval accuracy of TMPA estimates, especially for winter precipitation.

Table 5. Retrieval counts of sensors introduced into the TMPA processing for all grids over the Jinghe river basin on 11 January, 12 January, and the whole January in 2008, respectively.

\begin{tabular}{|c|c|c|c|c|c|c|c|}
\hline \multirow{2}{*}{ Source Number } & \multirow{2}{*}{ Sensor } & \multicolumn{2}{|c|}{11 January } & \multicolumn{2}{|c|}{12 January } & \multicolumn{2}{|c|}{ Whole Month } \\
\hline & & RTV7-R1 & RTV7-R2 & RTV7-R1 & RTV7-R2 & RTV7-R1 & RTV7-R2 \\
\hline 0 & no observation & 0 & 0 & 0 & 0 & 0 & 0 \\
\hline 1 & AMSU-B & 0 & 2 & 0 & 0 & 0 & 384 \\
\hline 2 & TMI & 89 & 89 & 17 & 17 & 605 & 536 \\
\hline 3 & AMSR & 56 & 56 & 0 & 0 & 719 & 719 \\
\hline 4 & SSMI & 115 & 15 & 5 & 0 & 321 & 141 \\
\hline 5 & F17 SSMIS & 0 & 0 & 0 & 0 & 0 & 0 \\
\hline 6 & MHS & 91 & 0 & 134 & 70 & 2934 & 827 \\
\hline 7 & spare sounder 1 & 0 & 0 & 0 & 0 & 0 & 0 \\
\hline 8 & spare sounder 2 & 0 & 0 & 0 & 0 & 0 & 0 \\
\hline 9 & spare sounder 3 & 0 & 0 & 0 & 0 & 0 & 0 \\
\hline 10 & F16 SSMIS & 0 & 21 & 0 & 0 & 0 & 242 \\
\hline 11 & F18 SSMIS & 0 & 0 & 0 & 0 & 0 & 0 \\
\hline 12 & spare scanner 6 & 0 & 0 & 0 & 0 & 0 & 0 \\
\hline 30 & $\begin{array}{l}\text { AMSU-B \& } \\
\text { MHS avg. }\end{array}$ & 0 & 170 & 0 & 137 & 0 & 1163 \\
\hline 31 & conical avg. & 0 & 11 & 14 & 25 & 371 & 684 \\
\hline 50 & IR & 209 & 196 & 390 & 311 & 12,410 & 12,664 \\
\hline $1,2, \ldots, 12+100$ & sparse-sample HQ & 0 & 0 & 0 & 0 & 0 & 0 \\
\hline \multicolumn{3}{|c|}{ Total retrieval counts and for all sensors } & 560 & & 560 & & 17,360 \\
\hline
\end{tabular}

\section{Conclusions and Recommendations}

In this study, we performed the first evaluation of the differences between "early" and "late" Version-7 TMPA-RT datasets by employing a high-density independent ground observation network over the Jinghe river basin, China. Our aim is to provide data users and algorithm developers with some valuable insights into the influence of missing one or two passive microwave sensors as inputs to the combined, multi-satellite precipitation retrieval algorithms. The findings of this study include:

1. Same as AMSU-B, the SSMIS-F16 inputs were also missed in the first Version-7 processing, which was not documented in the TMPA technical report [21].

2. The inclusion of AMSU-B and SSMIS-F16 substantially reduced the systematic biases associated with inadequate PMW samples in the "early" RTV7-R1 estimates, though it was not capable of further enhancing the skill of detecting rainy events. Over the whole Jinghe river basin, the daily bias value decreased from $43.99 \%$ of RTV7-R1 to $21.99 \%$ of RTV7-R2 (decreasing by $22 \%$ ). In RTV7-R2, AMSU-B (accounting for approximately $62 \%$ of newly added inputs) and SSMIS-F16 (about 33\%) mainly compensated for the decreased retrievals from the IR sensors. 
3. Spatially, the improvement primarily appeared in flat areas at lower elevations. Both the AMSU-B and SSMIS-F16 results presented here and the evaluations of other passive microwave sensors presented in [22] and [18] suggest that the topography-dependent biases will continue to remain an open issue for the multi-sensor precipitation retrievals even in the forthcoming GPM era.

4. In addition, the improvement exhibits an obvious seasonal dependence. For summer, the RTV7-R2 incorporating the AMSU-B and SSMIS-F16 retrievals generally outperformed the prior RTV7-R1. Taking the Jinghe river basin as example, the CC value rises from 0.56 of RTV7-R1 to 0.61 of RTV7-R2, meanwhile the BIAS decreases from $19.36 \%$ to 11.60 . For winter, this introduction is more effective in reducing the TMPA's systematic bias (decreasing from 155.55\% for RTV7-R1 to $8.15 \%$ of RTV7-R2) than the other three seasons, especially for large snowfall events. The retrieval counts analysis indicates that SSMIS-F16, AMSU-B, and IR jointly offered the principal supplements for the decreased cross-tracking MHS retrievals in the RTV7-R2 estimates during the snowfall events. The added imager SSMIS-F16 substitute partial MHS sounder overpasses and play a key role in improving the TMPA estimates, especially in winter.

Overall, our study verified that the data quality of TMPA estimates is sensitive to one or two important PMW sensors. Although the ground-based validation in this study is limited to a mid-sized basin at the middle and high latitudes, we believed that other regions in the globe might experience similar issues as well. We expect the assessment reported in this paper will provide a valuable reference for understanding the impact of missing passive microwave (PMW) inputs on the end product of multi-satellite precipitation products. For the algorithm developers, they should note this point in producing their multi-sensor merged precipitation products, including the upcoming Integrated Multi-satellitE Retrievals for GPM (IMERG). That means including a particular type of PMW sensors might produce an unexpected influence on the end products of IMERG. On the other hand, this study also highlights the need for special caution when using the Version-7 TMPA products before the release of the anticipated IMERG data. As the developers originally recommended, we further support the notion that TMPA users should switch to the newest Version-7 datasets as soon as practical. In particular, users should not utilize the "early" Version-7 TMPA datasets downloaded from the NASA FTP site between May 2012 and January 2013 for their applications or other studies. It is important to note that the newest Version-7 data can be identified by the file name suffix of "7R2". For more details, one can see "additional processing for Version 7" in the TMPA technical report.

\section{Acknowledgments}

This work was financially supported by National Natural Science Foundation of China (51379056, 51190090, 91437214) and Open Fund of State Key Laboratory of Satellite Ocean Environment Dynamics, Second Institute of Oceanography (SOED1414). Also this work is partially sponsored by the 111 Project (B08048), Key Laboratory of Water Science and Engineering, Nanjing Hydraulic Research Institute (Yk9414010), and State Key Laboratory of Remote Sensing Science (OFSLRSS201317). The authors wish to thank George Huffman for his helpful discussions and four anonymous reviewers for their constructive comments on the earlier version, which greatly improved the quality of this paper. 


\section{Author Contributions}

Bin Yong and Bo Chen designed the study, conducted the analysis, and wrote the manuscript; Yang Hong, Jonathan J. Gourley, and Zhe Li contributed to discussions and revisions, providing important feedbacks and suggestions.

\section{Conflicts of Interest}

The authors declare no conflict of interest.

\section{References}

1. Yong, B.; Chen, B.; Gourley, J.J.; Ren, L.; Hong, Y.; Chen, X.; Wang, W.; Chen, S.; Gong, L. Intercomparison of the Version-6 and Version-7 TMPA precipitation products over high and low latitudes basins with independent gauge networks: Is the newer version better in both real-time and post-real-time analysis for water resources and hydrologic extremes? J. Hydrol. 2014, 508, 77-87.

2. Yong, B.; Ren, L.; Hong, Y.; Gourley, J.J.; Tian, Y.; Huffman, G.J.; Chen, X.; Wang, W.; Wen, Y. First evaluation of the climatological calibration algorithm in the real-time TMPA precipitation estimates over two basins at high and low latitudes. Water Resour. Res. 2013, 49, 2461-2472.

3. Huffman, G.J.; Bolvin, D.T. Real-Time TRMM Multi-Satellite Precipitation Analysis Data Set Documentation. Available online: ftp://meso-a.gsfc.nasa.gov/pub/trmmdocs/rt/3B4XRT_doc_V7.pdf (accessed on 16 December 2013).

4. Huffman, G.J.; Adler, R.F.; Bolvin, D.T.; Nelkin, E.J. The TRMM multi-satellite precipitation analysis (TMPA). In Satellite Rainfall Applications for Surface Hydrology; Springer: New York, NY, USA, 2010; pp. 3-22.

5. Yong, B.; Hong, Y.; Ren, L.; Gourley, J.J.; Huffman, G.J.; Chen, X.; Wang, W.; Khan, S.I. Assessment of evolving TRMM-based multisatellite real-time precipitation estimation methods and their impacts on hydrologic prediction in a high latitude basin. J. Geophys. Res. 2012, 117, D09108.

6. Turk, F.J.; Mostovoy G.V.; Anantharaj V. Soil moisture sensitivity to NRL-blend high resolution precipitation products: Analysis of simulations with two land surface models. IEEE J. Selec. Top. Appl. Earth Obs. Remote Sens. 2010, 3, 32-48.

7. NASA GSFC FTP. Available online: ftp://trmmopen.gsfc.nasa.gov/pub/merged/ (accessed on 8 January 2014).

8. Yong, B.; Ren, L.; Hong, Y.; Wang, J.; Gourley, J.J.; Jiang, S.; Chen, X.; Wang, W. Hydrologic evaluation of multisatellite precipitation analysis standard precipitation products in basins beyond its inclined latitude band: A case study in Laohahe basin, China. Water Resour. Res. 2010, 46, W07542.

9. Adler, R.F.; Huffman, G.J.; Chang, A.; Ferraro, R.; Xie, P.; Janowiak, J.; Rudolf, B.; Schneider, U.; Curtis, S.; Bolvin, D.; et al. The version 2 Global Precipitation Climatology Project (GPCP) monthly precipitation analysis (1979-present). J. Hydrometeorol. 2003, 4, 1147-1167.

10. Nicholson, S.E.; Some, B.; McCollum, J.; Nelkin, E.; Klotter, D.; Berte, Y.; Diallo, B.M.; Gaye, I.; Kpabeba, G.; Ndiaye, O.; et al. Validation of TRMM and other rainfall estimates with a high-density gauge dataset for West Africa. Part II: Validation of TRMM rainfall products. J. Appl. Meteorol. 2003, 42, 1355-1368. 
11. Chiu, L.; Liu, Z.; Vongsaard, J.; Morain, S.; Budge, A.; Neville, P.; Bales, C. Comparison of TRMM and water district rain rates over New Mexico. Adv. Atmos. Sci. 2006, 23, 1-13.

12. Chokngamwong, R.; Chiu, L.S. Thailand daily rainfall and comparison with TRMM products. J. Hydrometeorol. 2008, 9, 256-266.

13. Ebert, E.E.; Janowiak, J.E.; Kidd, C. Comparison of near-real-time precipitation estimates from satellite observations and numerical models. Bull. Am. Meteorol. Soc. 2007, 88, 47-64.

14. Tian, Y.; Peters-Lidard, C.D.; Eylander, J.B.; Joyce, R.J.; Huffman, G.J.; Adler, R.F.; Hsu, K.-L.; Turk, F.J.; Garcia, M.; Zeng, J. Component analysis of errors in satellite-based precipitation estimates. J. Geophys. Res. 2009, 114, D24101.

15. Hossain, F.; Huffman, G.J. Investigating error metrics for satellite rainfall data at hydrologically relevant scales. J. Hydrometeorol. 2008, 9, 563-575.

16. Shepard, D. A two-dimensional interpolation function for irregularly-spaced data. In Proceedings of the 1968 23rd ACM National Conference, Las Vegas, NV, USA, 27-29 August 1968; ACM: New York, NY, USA, 1968; pp. 517-52.

17. Tian, Y.; Peters-Lidard, C.D. A global map of uncertainties in satellite-based precipitation measurements. Geophys. Res. Lett. 2010, 37, L24407.

18. Yong, B.; Liu, D.; Gourley, J.J.; Tian, Y.; Huffman, G.J.; Ren, L.L.; Hong, Y. Global view of real-time TRMM multi-satellite precipitation analysis: Implication to Global precipitation measurement mission. Bull. Am. Meteorol. Soc. 2015, doi:10.1175/BAMS-D-14-00017.1.

19. Behrangi, A.; Tian, Y.; Lambrigtsen, B.H.; Stephens, G.L. What does cloudsat reveal about global land precipitation detection by other spaceborne sensors? Water Resour. Res. 2014, 50, 4893-4905.

20. Behrangi, A.; Andreadis, K.; Fisher, J.B.; Turk, F.J.; Granger, S.; Painter, T.; Das, N. Satellite-based precipitation estimation and its application for streamflow prediction over mountainous western U.S. basins. J. Appl. Meteor. Climatol. 2014, 53, 2823-2842.

21. NASA GSFC FTP-Dcouments. Available online: ftp://precip.gsfc.nasa.gov/pub/trmmdocs/ 3B42_3B43_doc.pdf (accessed on 10 September 2014).

22. Tang, L.; Tian Y.; Lin X. Validation of precipitation retrievals over land from satellite-based passive microwave sensors, J. Geophys. Res. 2014, 119, 4546-4567.

(C) 2015 by the authors; licensee MDPI, Basel, Switzerland. This article is an open access article distributed under the terms and conditions of the Creative Commons Attribution license (http://creativecommons.org/licenses/by/4.0/). 